\title{
PUBLICITY IN MOBILE AND SOCIAL MEDIA
}

\author{
ATTILA ENDRE SIMAY ${ }^{1}-$ MIRKÓ GÁTI² $^{2}$ \\ ${ }^{1}$ Institute of Marketing and Media, Corvinus University of Budapest, Hungary \\ Email: attila.simay@uni-corvinus.hu \\ ${ }^{2}$ Institute of Marketing and Media, Corvinus University of Budapest, Hungary \\ Email:mirko.gati@uni-corvinus.hu
}

The twenty-first century brought with it the proliferation of new media. We carry mobile devices and smartphones with us nearly everywhere we go. Constantly hooked up to the world by these tools, the bigger question is why we are sometimes not available. Our personal networks have partly migrated to online social networks, and new networks now penetrate our everyday lives in the digital sphere. In this online survey research, the authors searched for insights into how important smartphones and Facebook, the most popular social media site in Hungary, have become in people's lives. The kinds of attitudes that characterise the use of these tools were analysed, especially in the case of privacy and the use of personal data. The aim of this research - by establishing the actual situation - is to show how modern media, publicity, and privacy are linked, and how people reveal themselves by their constant media presence.

Keywords: involvement, mobile media, privacy, publicity, smartphone, social media

JEL code: M15, M31 


\section{INTRODUCTION}

Recent technological developments, including mobile devices, have reformulated the separation between the public and the private spheres. The radical change in individual communications practice has also transformed the "publicity structure" of society and is reinterpreting the boundaries of public and private communication. By making phone calls (local, national, and international), the space and time constraints of personal communication can be overcome (Gálik - Urbán 2014). The rapid expansion of new infocommunications technology is changing the publicity perception of people involved in various communications situations. New social situations are being established, in addition to the contexts created by physical spaces, while the roles, expectations, and rules assigned to social situations are also changing. The line between public and private is becoming blurred; publicity is starting to encroach on the private sphere (Ferencz 2009). As Bohman (2004) stated, internet and computer-mediated communication is in connection with the political environment of a society, and it can change and contribute to a new sort of public sphere that is required for democratic deliberation. The internet's social role was already analysed in 2002, where the effects of internet use on communication, social involvement, and well-being were examined (Kraut et al. 2002). In this research, the positive and negative consequences of participating in online social roups were analysed, and many aspects (e.g. self-esteem, commitment to social norms) were connected to the strong social ties that people can build with the help of the internet. Other studies showed that people can form strong social bonds online that have positive carryover effects to their offline life (Parks - Roberts 1998). These early research results show that the social effects of the internet have been in the focus of academic interest for a long time. Gershuny (2002a; 2002b) conducted a time-series research of the internet's effect on society. He analysed the change in leisure patterns of internet users and non-users and found that these patterns changed in a way that users' publicly sociable activities increased, because they could manage their time better than their non-user counterparts.

Mobile devices are potentially capable of establishing confidential relationships on demand. This involves a virtually extended presence in everyday practice and space. Mobile communication accelerates information exchange between people and contributes to social interactions. Mobile technologies provide people with new opportunities to organise their everyday life in space and time. Consequently, they can change the perceived space and time constraints. Mobile devices allow for mobile intimacy and presence, in which the participants share seemingly small and insignificant pieces of information about their activities and whereabouts, therefore potentially enabling an intimate connection in any moment of social life (Arminen - Weilenmann 2009). 
According to research data, privacy-related issues do not affect users' readiness to personalise their phones with applications, even if doing so raises questions of security. The level of privacy protection decreases with the use of mobile applications, since users use them to share more and more personal information (Han et al. 2015). Moreover, they are less and less circumspect, not only in terms of the quantity but also in terms of the quality of the information they share (Gronli et al. 2013).

Research from Taiwan found that the use of mobile applications potentially offers perceived benefits for users, benefits that are bigger than the potential degree of risks they perceive (Wang et al. 2016). This is not a unique result. Other data also show that in the case of young Facebook users, there are no private-sphererelated considerations; they do not perceive any risk, say, when checking in, i.e., sharing information regarding a given location on their smartphone (Kim 2016).

Based on the results from Taiwan, personalised services, in which users have self-representation with portraits and personal information, are seen as social ties, which promote users' confidence in mobile applications. These services therefore encourage smartphone users to share information. The intention of symbolic selfexpression also encourages people to share personal information via mobile applications. By sharing these personal data, they develop, maintain, and improve their personal relationships via mobile applications (Wang et al. 2016).

Although security risks are strongly associated with smartphone usage, users' perceived risk is low (Jones - Chin 2015). In connection with the perceived risks in Taiwan, the severity of the loss of personal data is much greater than losing control of that data (this is to be analysed in the Hungarian context, too). However, the perceived risks run counter to the users' intentions to share information via mobile applications: people do not share information because of the risk of disclosure of personal information on social media, for example (Wang et al. 2016). "Social media is defined as a group of internet-based applications that build on the ideological and technological foundations of web 2.0 and allow the creation and exchange of user-generated content" (Kaplan - Haenlein 2010: 61). Social media influenced consumer behaviour significantly, and many - previously private - consumer activities became public due to social media (Bányai 2016; Veszelszki 2018).

\section{FACEBOOK AND PRIVACY}

The examination of the relationship between mobile applications and the private sphere - including the use of Facebook on smartphones - in a Hungarian context is a relevant and actual issue. In $2015,92 \%$ of both households and private individuals over the age of 14 had mobile phones, and the proportion of smartphones 
was showing a dynamic growth rate: $48 \%$ of people over the age of 14 had smartphones, compared to $11 \%$ in $2011\left(\mathrm{NMHH}^{1} 2016 \mathrm{a}\right)$.

Further examination of public internet usage also shows the significance of Facebook in the online space used by Hungarian people. Based on an NMHH report (NMHH 2016b), Facebook was the most widely used internet-based social website in 2015 in Hungary with $86 \%$ of internet users. Its use is constantly increasing: $71 \%$ and $32 \%$ used Facebook for written chat and audio chat, respectively, compared to $61 \%$ and $22 \%$, respectively in 2014 . Facebook is outpacing Skype, Viber, and all other applications used in Hungary. The NMHH report also shows that $66 \%$ of smartphone owners have installed the Facebook application and 52\% have installed Facebook Messenger, the two most popular applications in Hungary in 2015. Facebook is therefore the dominant social media platform, and a widespread smartphone application (NMHH 2016b). Thanks to the spread of smartphones, the use of internet communities has appeared on mobile phones, too. In the following sections, and related to the main topic of this article, the term smartphone is used when mobile phones are mentioned in connection with internet use and social media.

As a starting point, this research focused on Hungarian and Taiwanese internet and social media usage, because it can be assumed that internet usage entails the rapid growth of the use of social networks. In Taiwan, internet penetration is $83.8 \%$ (Taipei Times 2014), while in Hungary it is $68 \%$ (NMHH 2016a). Facebook penetration in Taiwan is $76.7 \%$, while in the case of Hungarian internet users this value is $86 \%$, but the Taiwanese value is higher in proportion to its population (Internet World Stats 2016). On the whole, Taiwan is the most Facebook-using country based on total population (Taipei Times 2014). Typical shared content includes images, full names, dates of birth, email addresses, postal addresses, telephone numbers, sexual orientation, group memberships, and sometimes names of family members, all of which pose security risks.

One of the driving forces behind online communities is information sharing. Users create and share content with each other. Moreover, the majority of users do not restrict the accessibility of their online profiles, even if they generally pay attention to the confidentiality of private information (Kisekka et al. 2013).

As regards considerations in connection with privacy protection, Kim (2016) did not find any significant correlation between private-sphere-related considerations and Facebook check-ins. People who do not share any location-related information on Facebook are typically less interested in location-related information sharing anyway. People usually share personal data in exchange for benefits.

NMHH: Nemzeti Média- és Hírközlési Hatóság / Hungarian National Media and Infocommunications Authority. 
Those who have a lower level of concern in connection with data management prefer to use applications which they perceive to be useful, including locationrelated information sharing. Greater smartphone involvement worsens the considerations regarding privacy protection. The more committed a person is to using a smartphone, the more likely they are to share content about themselves on Facebook, even location-related information. It is important to note that people who previously shared location-related information on Facebook were typically more familiar with the data management settings of Facebook and were not worried about their privacy protection to a great extent. Location- or advertisementrelated information sharing on Facebook is more common when we talk about users who have no previous experience with sharing location-based information on social media but who are heavily dependent on the use of their smartphone (Kim 2016).

This raises the question of who generates word-of-mouth on Facebook. Online word-of-mouth is a positive or negative statement disclosed by current, potential, or former consumers about a product, service, or company and made available via the internet platform (Horváth - Bauer 2013). Word-of-mouth has several underlying motives like opinion seeking, opinion giving, and opinion passing, and it can be concluded that opinion seeking behaviour has a positive effect on customer satisfaction (Nagy et al. 2016: 154-156.), so from the marketers' point of view the importance of word-of-mouth is elemental. These considerations suggest that young people using smartphones who are addicted to Facebook - especially those who are not aware of the potential dangers of sharing personal information - are less worried about the protection of their privacy and are more likely to spread online word-of-mouth.

The term "consumers" is used in this article to emphasize individuals who use different products, but in the context of social media, it is indispensable to mention the term "prosumers" who make common value creation activities with the producer that result in the production of products (Xie et al. 2008). This term is based on the phenomenon of "value co-creation", where value is created in the process of consumption, where participation is involved by the co-production of the "prosumers" and the producers (Lusch - Vargo 2006: 284), mainly in the context of social media.

In 2010, due to changes in the data management rules, the amount of public information on Facebook increased. More information became available about people who were not sensitive enough about protecting their personal data. This resulted in a shrinkage of the private sphere. There were no significant differences between users of the old and new data management system and rules. Comparisons show that fewer and fewer people are sharing data about birthdays and political orientations publicly on their profiles, while after 2010 an increase could 
be observed in the case of sharing place of residence and study. The sharing of areas of interests (e.g. books, films, or music) remained unchanged (Stutzman et al. 2012).

Research from Turkey also shows that the more conscious users are about the protection of their privacy, the less likely they are to share images in their profiles. They typically have fewer friends on Facebook. Users who have experience in information technology are more sensitive about protecting their personal data and are more reluctant to provide personal information. Moreover, they typically do not 'like' any activities or content, and if they provide such data, they do not make it public. Women typically pay more attention to the protection of their basic personal data than men. According to Külcü and Henkoglu (2014), users who registered after 2010 pay the same attention to the sharing of information like images, residence, basic information, and liked content, as those who had registered previously. However, in 2010, Facebook privacy policies changed. These changes led to personal data previously hidden by users becoming available to everyone to some extent, and therefore the degree of privacy decreased.

This is somewhat consistent with research from America, which states that women are more cautious about making content public than men. However, it also states that the use of smartphones increases the probability that users will restrict accessibility to personal data and profiles. Smartphones therefore contribute to the protection of information, too. Elderly users also treat personal information confidentially and tend to set access restrictions to their content (Kisekka et al. 2013). Therefore, smartphones as a medium for accessing Facebook may promote consciousness towards and protection of the private sphere.

\section{RESEARCH AND SAMPLE}

The majority of the survey participants were young people, justified by the fact that according to the NMHH report (2016a) around half of those aged between 15 and 35 had smartphones in 2015, while this proportion severely decreases in older age groups. The report also shows that $72 \%$ of the total population consider smartphones to be indispensable in their everyday lives, a 7\% increase compared to 2014. The background to this may be an increase in the number of smartphone applications and the accessibility of social media, since the proportion of those accessing the internet via smartphones reached $18 \%$ by 2015 , a $5 \%$ increase on the previous year (NMHH 2016a).

It was important to obtain internationally comparable results and, with the help of already tested scales, to ask respondents how important the protection of the 
private sphere is on the smartphone and Facebook platforms. Questions related to smartphone applications were adapted to the private sphere, following Wang et al. (2016), while the Facebook-related questions were based on Kim (2016).

The aim of this research is three-fold. First (research aim 1), to observe the behaviour of the two models on an actual Hungarian sample by means of an international comparison and to determine the differences responsible for the main divergences and their combined effect. Second (research aim 2), to make a cultural comparison and test the operation of the model in a Hungarian environment, to reveal the potentially changing nature and context of certain consumer and publicity-related attitudes. Third (research aim 3), by revealing the correlations between the two international models, to find new results related to the sharing of consumer information, which would help foster a deeper understanding of consumer attitudes regarding mobile and social media platforms.

In line with the context of new media, the research was carried out within the framework of an online survey, which sought to minimise the potential distortions deriving from the difference between the platforms being surveyed and the subject of the survey. Furthermore, the online survey method allowed research in the shortest possible time, on the largest possible sample, thus minimising costs incurred. Participants were students of Corvinus University of Budapest (CUB), and, to a lesser extent (20\%) of the Károli Gáspár University of the Reformed Church in Hungary (KGURCH). Data collection was performed between 19 April 2016 and 11 May 2016, within a three-week interval to eliminate potential distortions which could have been derived from a wider interval. After the data cleansing, the final sample size was 1,088.

The proportion of women and men in the sample was $61.8 \%$ and $38.2 \%$, respectively. The higher proportion of women derives from the characteristics of the sample of students and in that regard, the students' composition in the university courses involved in the research. The average age of the sample was 21.71 years (standard deviation: 3.39 years). Students in the sample belonged to the age group (mostly of 19-25 years) that possesses the most smartphones according to the NMHH report (2016b); $90 \%$ of the respondents were 25 years old or younger. In conclusion, $94.2 \%$ of the students in the sample live in cities and nearly $90 \%$ had average or above-average salaries.

Sample subjects had a smartphone for 10 years on average (standard deviation: 2.59 years), and $92.6 \%$ considered smartphones important in their lives (of which $42.8 \%$ found them especially indispensable).

As regards internet and social media use, sample subjects spent an average of approximately 3 hours each day on the internet, of which approximately half ( 1.5 hours) was spent on social media. They registered on an internet-based social 
website 8 years ago on average (standard deviation: 2 years) and 6 years ago on Facebook. Nearly $60 \%$ of the sample subjects considered Facebook an important factor in their lives.

\section{Methodology}

Besides certain international comparisons, the purpose of this research was to summarise all the latent variables and their connections in a unified model. Therefore, partial least squares (PLS) path modelling was applied. This method can estimate very complex models with numerous latent and manifest variables. It has less rigorous conditions concerning the distribution and errors of the different variables. At the same time, it can work with both reflective and formative measurement models. However, the use of PLS requires prudence, because it is not so strict regarding the representativeness of the sample. PLS path modelling does not give any global fit measure for the goodness of fit. As Cronbach's Alpha has the condition that every indicator is equally reliable, PLS ranks the indicators based on their reliability, so it gives a more reliable combination. Combined reliability considers the different loadings of indicators, and these loadings can be interpreted as Cronbach's Alpha (Henseler et al. 2009). PLS is similar to regression, but it models structural paths together, so theoretical connections among latent variables and measurement paths are identifiable (i.e., relationships among latent variables and their indicators) (Chin et al. 1996).

Measurement loadings (or correlations) evaluate the reliability of certain items with the right constructs. Items under 0.4 or 0.5 loading are generally excluded from the model, but it is not uncommon to exclude items with a value of 0.6 . The main purpose of PLS is to minimise errors, i.e., to maximise the explained variance in the case of every endogenous construct (Hulland 1999). In this study, values under 0.6 were excluded to maximise the explanatory power of the final model.

SmartPLS 2.0 was applied to evaluate the survey data (Ringle et al. 2005). The results of the survey were tested in 300 iterations. A bootstrapping method was then used to test the significance of connections in the model by generating 200 probability subsamples in order to assure the proper estimation of standard errors (Chin 2001).

\section{RESULTS}

With the help of the data derived from the Hungarian sample, the original model of Wang et al. (2016) was first tested. Some influencing factors of the two original models and the combined model, which will be presented later, were exam- 


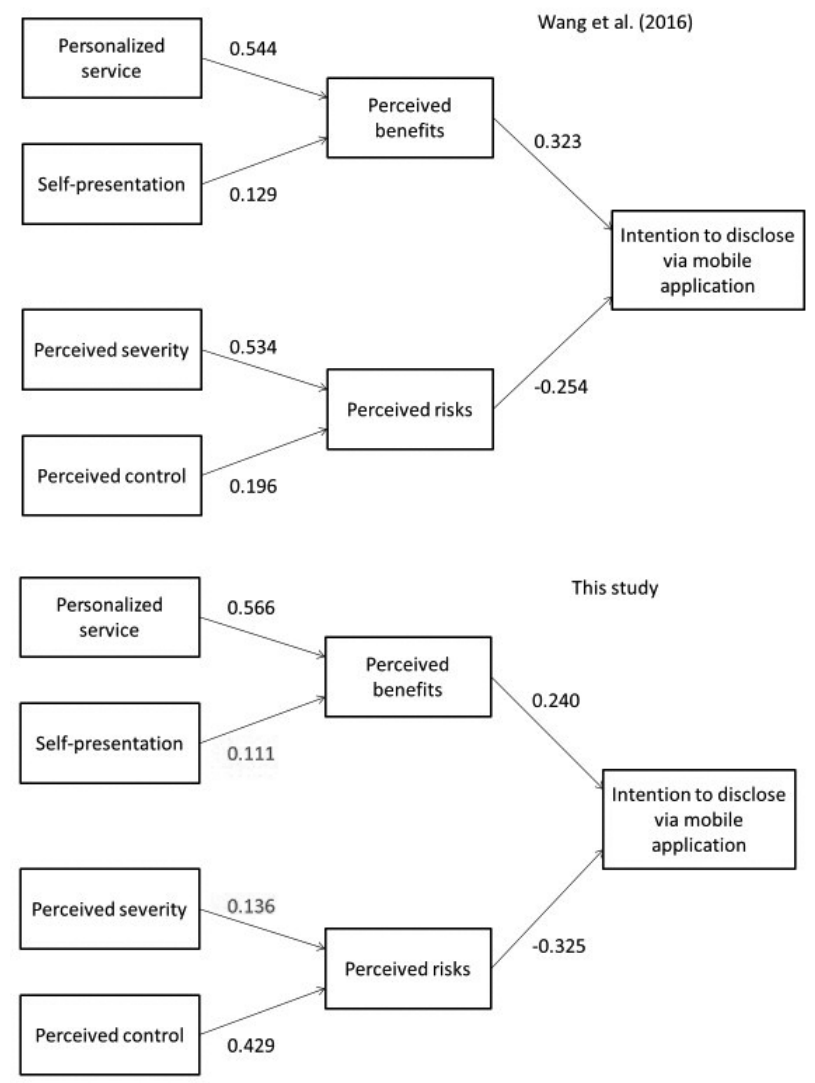

Figure 1. Indicators of information share of consumers

Source: authors, based on Wang et al. (2016).

ined with a PLS path analysis. An exploratory factor analysis was also used to ensure the togetherness of certain theoretical constructs, and to be certain that non-significant correlations were omitted. Compared to the Taiwanese results, the Hungarian sample showed several interesting differences. In the case of the severity of the risk, the indicator related to the loss of photos had to be deleted due to its relatively low weight (0.600), which suggests respondents did not view losing privacy-related photos as a problem.

Significant differences can be observed compared to the original model (Figure 1). In the Hungarian research, the contribution of self-presentation (how users portray themselves in the digital sphere) to the perceived benefits is not significant. However, the origin of the perceived risks shows an even more sig- 
nificant difference. While in the Taiwanese research, perceived risks primarily arose from the severity of data loss, in the case of the Hungarian respondents, this factor did not show a significant correlation with the perceived risks; Hungarian users are more concerned about losing control of their data rather than losing the data itself.

Another difference is regarding the publication of data. In the case of Hungarian users, the contribution of the perceived benefits to their willingness to share information via their smartphones is lower, while the dissuasive effect of the perceived risks is higher than in the Taiwanese research, i.e., users do not see the advantage of sharing personal data and are more fearful about sharing it. This is more or less a reverse situation compared to the results of the original research.

Kim's (2016) results were tested by a structural analysis of the data of the Hungarian sample. Based on the data analysis, self-development (e.g. checking publicly on a social networking site to learn new things, or to enhance one's expertise in something) and reputation motivate Hungarian respondents to share information related to a given location on Facebook. The contribution of other variables is not significant. Convictions in connection with privacy protection on Facebook are significantly affected by convictions about privacy in general, which matches with the original research.

Regarding location-related information sharing, the question about general conviction - namely that good companies, services, and locations should be supported - had to be eliminated due to its low weight (0.576). Probably the too general phrasing of the question, not clearly related to recommendations and word-of-mouth, may be why responses showed that it has little correlation with the popularity of certain locations/services. However, the differences suggest that in the case of those surveyed, in connection with privacy protection, neither general nor Facebook-related convictions have any influence on the users' information and recommendation sharing of a given location on their smartphones. Kim (2016) found in the USA that general convictions do not affect the publication of information and word-of-mouth, while Facebook-related convictions do. This also contradicts the American data in the model that smartphone use does not have any significant effect on information sharing via smartphones; unless the self-development and reputation variables are eliminated.

\section{THE COMBINED MODEL}

The aim of the present research was not only to make international comparisons with other research results, but also to reveal further potential correlations in connection with consumers' information sharing, especially via media like Facebook 
and smartphones, by combining certain variables. After testing the results of the two international research studies on the Hungarian sample between each variable, a combined model was created in the hope of a more complex comprehension (Figure 2).

In this combined model, it has been justified that information sharing via smartphones may include word-of-mouth related to a given location. The extent of the contribution showed a moderately weak (0.226) but significant correlation. Having tested the correlation inversely, it was not significant; therefore, word-ofmouth contributes to the intention to disclose and not the other way round.

During the repositioning of non-significant indicators and the testing of the model, general attitudes did not show significant correlation with the perceived risks, while the Facebook and privacy protection-related variable did. The correlation proved to be moderately weak (0.304). At the same time, because of the new explanatory variable, the contribution of the former two variables to the perceived risks decreased, and only control proved to be significant with a value of 0.320 .

Thus, digging deeper into the data, it turned out that general privacy-protection-related attitudes showed a moderate contribution to control (0.536), but only a moderately weak correlation to concerns about the severity of data loss $(0.384)$. Regarding the degree of control, the correlation is two-directional, while in the case of the severity of data loss, it is not. Consequently, it seems that there is no direct connection between the general attitude related to privacy protection and the perceived risks, but this attitude affects variables which eventually influence the perceived risks.

In addition, in the case of mobile phone involvement, there is no significant correlation between either the intention to disclose via mobile application, or the perceived benefits leading to them, or to personalised services. No significant correlation with the risk or its explanatory variables could be detected. In contrast, a mutually significant correlation can be found with self-presentation; the strength of the correlation is moderately weak in both directions (0.355). Still, self-presentation does not become an explanatory variable of the perceived benefits, since self-presentation does not have a significant effect on the perceived benefits in the Hungarian sample.

However, since both mobile phone involvement and attitudes related to privacy protection were eliminated from the group of variables which explain word-of mouth regarding a given location being non-significant elements, self-development together with commitment towards check-in also showed significant correlation with word-of-mouth. Consequently, information sharing of certain locations via Facebook on smartphones can be explained by the commitment towards check-in, and the given users' motivations of self-development and reputation. 
Information sharing via mobile applications can therefore be explained by three factors in the following model (Figure 2). Promotional agency and the perceived benefits of information sharing contribute positively, while the perceived risks contribute negatively. The strongest correlation in this three-factor model may be with perceived risks. This result may also mean that Hungarian respondents have considerable fears when deciding to share their data. This is followed by promotional agency motivations, i.e., how much a user tends to use word-of-mouth, while the weakest explanatory factor is the expected benefits of the sharing of personal information.

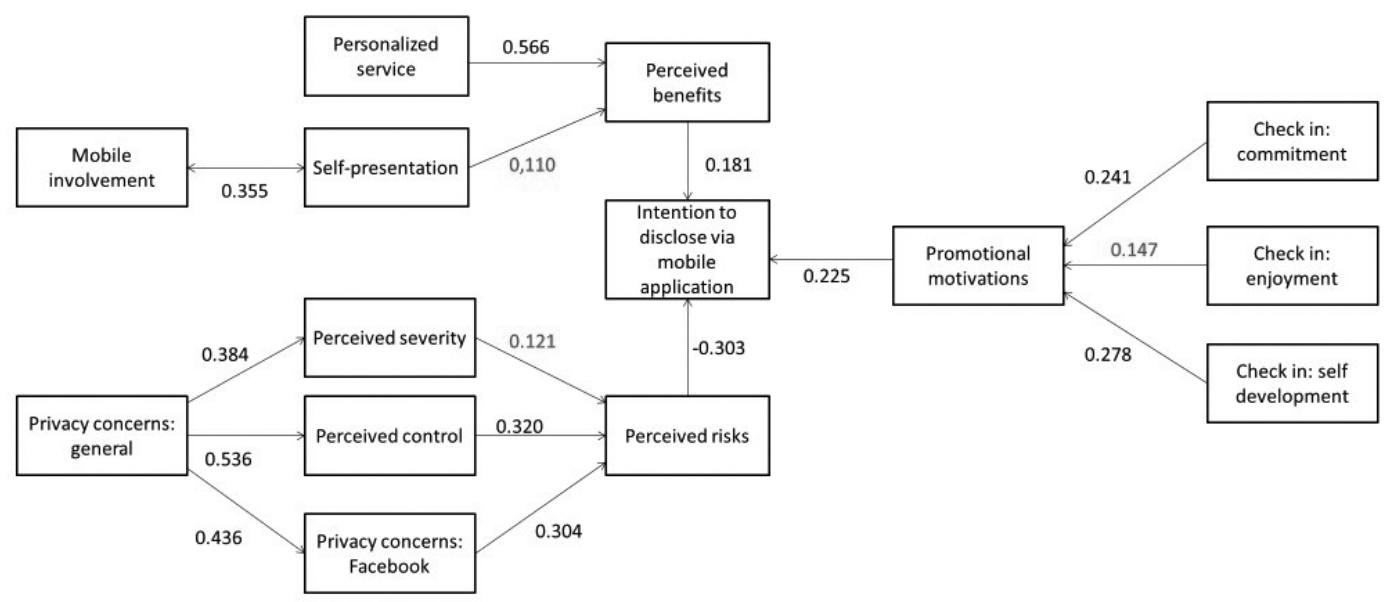

Figure 2. Combined model related to information share

Source: authors, based on Wang et al. (2016) and Kim (2016)

\section{CONCLUSIONS}

Based on the primary analysis, the following conclusion can be made, taking into consideration the differences between the Taiwanese (Wang et al. 2016) and the Hungarian research (Figure 1): in relation to privacy, those surveyed consider the loss of their photos a less serious problem than was observed in the international sample (addressing research aims 1 and 2). This is an interesting result, since the role of photos is hence shown to be on a different level of importance and it is possible that it has to be treated in a different way than the intention to disclose certain content (e.g. text). 
As a result of the primary research, the contribution of self-presentation to the perceived benefits is not significant, i.e., in this case, the sample subjects are motivated by an external opportunity and not an internal driving force to perceive information sharing to be beneficial. From this point of view, a characteristic of the Hungarian sample is that they are willing to share various types of information as a result of a kind of opportunistic, external-confirming force (research aims 1 and 2).

While in the Taiwanese research (Wang et al. 2016), the perceived risks primarily arose from the severity of the data loss the respondents suffered, in the case of the Hungarian sample the reason for the perceived risks was different. In the Taiwanese research (Wang et al. 2016), content and the importance of the lost data are more important. In the present research, the perceived risks include unauthorised access to data and the possibility of their loss. That is to say, for people in the Hungarian sample, losing their bank information is not as crucial an issue as somebody accessing their information (research aims 1 and 2).

In the attitude analysis of the Hungarian sample, it can be observed that along with the various data publication features, in the case of the opportunistic attitude - i.e., to obtain benefits from data transmission - the desire to avoid possible problems is more evident. Based on this, it can be concluded that for respondents in the Hungarian sample, the fear of a data breach is stronger than the positive expectations of benefits potentially deriving from the provision of the data (research aims 1 and 2).

Based on the primary analysis, the following conclusions can be made, taking into account the differences between the American (Kim 2016) and the Hungarian research: It is interesting that in the Hungarian sample respondents typically shared information with others in order to improve their own fame - self-development and reputation - while the other influencing factors do not have any significant effect on the extent of the transmission (research aims 1 and 2).

It matches with the original research (Kim 2016), that Facebook-related convictions in connection with privacy protection are significantly affected by general convictions, i.e., general assumptions affect specific attitudes related to a given social media platform and privacy in a logical way. Hence, the narrowed sub-questions of this research may follow directly from the general attitudes. On the contrary, none of the privacy-related convictions influences how much users are willing to share information (or maybe recommendations) via their smartphones, while according to Kim (2016), convictions related to Facebook affect disclosure of information and word-of-mouth (research aims 1 and 2). Based on this - according to the results of the Hungarian sample - actual information sharing is not dependent on underlying convictions. This result is not nuanced by the 
fact that mobile phone involvement does not have any significant influence on information sharing either.

New correlations have been revealed compared to the original models. Several factors contribute to the intention to disclose which jointly derive from functions created by social media opportunities (Figure 2). Perceived consumer authorisation and communication related to contents created by other people (e.g. like, comment, sharing) contribute to the intention to disclose. The role of word-ofmouth is therefore significant in the sense that it determines to what extent respondents share information in social media (research aim 3).

Another interesting correlation is that the general, privacy-protection-related attitudes have moderate correlation with control and only weak correlation with concerns about the severity of data loss. Based on the data, it can be concluded that general privacy-protection-related concerns do not affect the perceived risks directly; however, they influence all the factors affecting the perceived risks (severity of data loss, control, online privacy concerns) (research aim 3).

It is interesting that mobile phone involvement is not connected to the intention to disclose via mobile application or the perceived benefits implied, or even personalised services. After mobile phone involvement and the privacyprotection-related attitudes were eliminated from the group of variables explaining word-of-mouth, self-development and commitment towards check-in became significantly correlated with word-of-mouth. Thus, information sharing of a given location via Facebook on smartphones can be explained by the commitment towards check-in and the given user's motivations related to self-development and reputation but cannot be explained by the enjoyment-like nature of checking in (research aim 3).

Overall, information sharing via mobile applications depends on three factors. It is positively affected by promotional agency (research aim 3). Consequently, if users are willing to share information for marketing communications purposes (role of word-of-mouth), then it is more typical that they share general information via mobile applications (research aim 3). The perceived benefits of information sharing also positively affect the intention to disclose, especially by means of the opportunities of personalised services (research aim 3). Thirdly, perceived risks have a typically negative contribution to the intention to disclose. Furthermore, the strongest correlation in the three-factor model is with the perceived risks (research aim 3). Therefore, in the case of the Hungarian respondents, it is their fears which play the greatest role when they decide to share their data. This is followed by promotional agency motivations - i.e., how much users tend to use word-of-mouth - and finally, the explanatory variable which plays the smallest role in the group of expected benefits of personal information sharing. 
Besides the described theoretical correlations, this research can also be useful from a practical point of view for companies using mobile and social media. Based on the results the "more relaxed" user attitude towards various visual contents - regarding privacy protection-related issues - may be key data for marketing research and marketing communications companies, too. It is worth intensifying users' intention to disclose (which is more significant if they get external benefits) by means of external confirmations (incentives, gifts, etc.) to make it a rich source of social media content later. Another suggestion is that as the Hungarian sample had significant fears deriving from data loss, companies should highlight the security of user data to motivate people to use their services. The emphasis on self-development and reputation - and the users' motivation to show themselves on certain platforms - may encourage companies to provide an opportunity for the completion of the user self (e.g. consumer authorisation opportunities). The role of word-of-mouth in information sharing envisages that the word-of-mouth activity initiated by users could be supported on mobile and social media. The treatment of users' fears and the reduction of possible reasons of privacy protection-related concerns (e.g. transparent data protection principles, procedures) may also lead to a bigger quantity of information mentioned by users.

This research has its limitations. The methodology is not built on a representative sample; therefore, the research results can only be generalised to a limited extent and refer only to the most typical tendencies. The international comparison, i.e., the differences between the Hungarian and the international sample suggest that further differences may be found by examining other nations. This is both a barrier and an opportunity of the present research. The examined social media correlations and the achievements of mobile technology change rapidly, consequently, as time passes, the examined processes may change so much as a result of technological development that the questions may become outdated, even in a couple of years compared to 2016. The turbulent atmosphere also entails the creation of new platforms, which implies that the relevance of the examined platform (e.g. Facebook) can be questioned. Data management rules and the consumers' reaction to them also undergo continuous change - which in turn derives from the nature of the turbulent atmosphere - so these characteristics have to be taken into account when assessing the degree to which this field lends itself to research Another possible limit of the research may be that the primary research principally examined perceived variables while real behaviour remained hidden in many cases. Consequently, it would have been useful to make a content analysis of certain platforms of social media, using an arsenal of observation methodologies. 
Considering these limitations, multiple cross-sectional research studies may be suggested within the framework of a temporal comparison in the future, where consumer presence, which has changed over time, and the change of attitudes towards publicity could be revealed. In the future, examination of other types of social media, including actual platforms, should also be considered, taking into account the special features of the platform and the results of the present research. In the case of a social media platform like Instagram - where visual image content is emphasised instead of text - how does personal data protection work and what attitudes do consumers have towards it? If the analysis of image data does not cause relatively massive losses for consumers as compared to other types of data, then it should be revealed to what extent these losses affect certain factors of consumer presence and publicity. Finally, a future research avenue may be an observation to map real behaviours on social media platforms by applying the methodology of content analysis with the objective to test the validity of this research and to get new insights in connection with the topic.

\section{REFERENCES}

Arminen, I. - Weilenmann, A. (2009): Mobile Presence and Intimacy - Reshaping Social Actions in Mobile Contextual Configuration. Journal of Pragmatic 41(10): 1905-1923.

Bányai, E. (2016): The Integration of Social Media into Corporate Processes. Society and Economy 38(2): 239-259.

Bohman, J. (2004): Expanding Dialogue: The Internet, the Public Sphere and Prospects for Transnational Democracy. The Sociological Review 52(s1): 131-155.

Chin, W. W. (2001): PLS-graph User's Guide, version 3.0. Soft Modeling Inc., Houston.

Chin, W. W. - Marcolin, B. - Newsted, P. (1996): A Partial Least Squares Latent Variable Modeling Approach for Measuring Interaction Effects: Results from a Monte Carlo Simulation Study and Voice Mail Emotion/Adoption Study. International Conference on Information Systems 1996, Proceedings, pp. 21-41.

Ferencz, M. (2009): Értékek az internetes hálózati kommunikációban [Values in Internet Network Communication]. PhD Dissertation, Corvinus University of Budapest.

Gálik, M. - Urbán, Á. (2014): Médiagazdaságtan [Media Economics]. Budapest: Akadémiai Kiadó.

Gershuny, J. (2002a): Social Leisure and Home IT: A Panel Time-Diary Approach. It \& Society, 1(1): 54-72.

Gershuny, J. (2002b). Mass Media, Leisure and Home IT: A Panel Time Diary Approach. IT and Society 1(2): 53-66.

Gronli, T.-M. - Ghinea, G. - Bygstad, B. (2013): Exploring Solutions for Mobile Companionship: A Design Research Approach to Context-Aware Management. International Journal of Information Management 33(1): 227-234.

Han, S. - Min, J. - Lee, H. (2015): Antecedents of Social Presence and Gratification of Social Connection Need in SNS: A Study of Twitter Users and Their Mobile and Non-Mobile Usage. International Journal of Information Management 35(4): 459-471. 
Henseler, J. - Ringle, C. M - Sinkovics, R. R. (2009): The Use of Partial Least Squares Path Modelling in International Marketing. In: Sinkovics, R. R - Ghauri, P. N. (ed.) New Challenges to International Marketing. Emerald Group Publishing Limited, pp. 277-319.

Horváth, D. - Bauer, A. (2013): Marketingkommunikáció [Marketing Communications]. Budapest: Akadémiai Kiadó.

Hulland, J. (1999): Use of Partial Least Squares (PLS) in Strategic Management Research: A Review of Four Recent Studies. Strategic Management Journal 20(2): 195-204.

Internet World Stats (2016): Asia Marketing Research, Internet Usage, Population Statistics and Facebook Information. http://www.internetworldstats.com/asia.htm\#tw, accessed 10/11/2016.

Jones, B. - Chin, A. (2015): On the Efficacy of Smartphone Security: A Critical Analysis of Modifications in Business Students Practices over Time. International Journal of Information Management 35(4): 561-571.

Kaplan, A. M. - Haenlein, M. (2010): Users of the World, Unite! The Challenges and Opportunities of Social Media. Business horizons 53(1): 59-68.

Kim, H.-S. (2016): What Drives You to Check You to Check in on Facebook? Motivation, Privacy Concern, and Mobile Phone Involvement for Location-Based Information Sharing. Computers in Human Behaviour 54: 397-406.

Kisekka, V. - Bagchi-Sen, S. - Rao, H. R. (2013): Extent of Private Information Disclosure on Online Social Networks: An Exploration of Facebook Mobile Phone Users. Computers in Human Behavior 29(6): 2722-2729.

Kraut, R. - Kiesler, S. - Boneva, B. - Cummings, J. - Helgeson, V. - Crawford, A. (2002): Internet Paradox Revisited. Journal of Social Issues 58(1), 49-74.

Külcü, Ö. - Henkoglu, T. (2014): Privacy in Social Networks: An Analysis of Facebook. International Journal of Information Management 34(6): 761-769.

Lusch, R. F. - Vargo, S. L. (2006): Service-Dominant Logic: Reactions, Reflections and Refinements. Marketing Theory 6(3): 281-288.

Nagy, A. - Kemény, I. - Szücs, K. - Simon, J. - Kiss, V. (2017): Are Opinion Leaders More Satisfied? Results of a SEM Model about the Relationship between Opinion Leadership and Online Customer Satisfaction. Society and Economy 39(1): 141-160.

NMHH (2016a): Lakossági internethasználat - online piackutatás 2015 [Household Internet Usage - Online Market Research]. http://nmhh.hu/dokumentum/170534/lakossagi internethasznalat 2015 teljes.pdf, accessed 02/05/2016.

NMHH (2016b): Távközlési szolgáltatások használata a lakossági felhasználók körében 2015. http://nmhh.hu/dokumentum/169926/lakossagi_tavkozles_2015_piackutatasi_jelentes.pdf, accessed 08/05/2016.

Parks, M. R. - Roberts, L. D. (1998): Making MOOsic': The Development of Personal Relationships on Line and a Comparison to Their off-Line Counterparts. Journal of Social and Personal Relationships 15(4): 517-537.

Ringle, C. M - Wende, S - Will, S. (2005): SmartPLS 2.0 (M3) Beta. http://www.smartpls.de, accessed 15/07/2016.

Stutzman, F. - Grossy, R. - Acquisti, A. (2012): Silent Listeners: The Evolution of Privacy and Disclosure on Facebook. Journal of Privacy and Confidentiality 42(2): 7-41.

Taipei Times (2014): Taiwan Likes Facebook, Has Highest Penetration. http://www.taipeitimes. com/News/biz/archives/2014/02/28/2003584495, accessed 10/11/2016.

Veszelszki, Á. (2018): Like Economy: What is the Economic Value of Likes? Society and Economy 40(3): 417-429. 
Wang, T. - Duong, T. D. - Chen, C. C. (2016): Intention to Disclose Personal Information via Mobile Applications: A Privacy Calculus Perspective. International Journal of Information Science Management 36(4): 531-542.

Xie, C. - Bagozzi, R. P. - Troye, S. V. (2008): Trying to Prosume: toward a Theory of Consumers as co-Creators of Value. Journal of the Academy of Marketing Science 36(1): 109-122.

Open Access. This is an open-access article distributed under the terms of the Creative Commons Attribution 4.0 International License (https://creativecommons.org/licenses/ by/4.0), which permits unrestricted use, distribution, and reproduction in any medium, provided the original author and source are credited, a link to the CC License is provided, and changes - if any - are indicated. (SID_1) 